\title{
SAN JOSÉ: DEPOSITARIO DEL MISTERIO DE DIOS A LA LUZ DE LA EXHORTACIÓN APOSTÓLICA "REDEMPTORIS CUSTOS"
}

\author{
St. Joseph: depository of the mystery of god in the \\ light of the Apostolic Exhortation "Redemptoris custos"
}

Víctor Pablo Soto Rivas

Universidad Femenina Sagrado Corazón: victorsotor@unife.pe

ID ORCID: 0000-0002-0595-2073

\section{RESUMEN}

El presente artículo tiene como propósito reflexionar sobre la figura de San José como depositario del misterio de Dios a la luz del Capítulo II de la Exhortación Apostólica "Redemptoris Custos" para revalorar la participación de este insigne Patriarca en el plan de salvación pues como indica el mismo documento del Papa: "...José de Nazaret participó en este misterio como ninguna otra persona, a excepción de María, la Madre del Verbo Encarnado. Él participó... comprometido en la realidad del mismo hecho salvífico, siendo depositario del mismo amor...". (RC 1). Sobre todo, conoceremos en este artículo la participación de San José en el misterio divino como Esposo de María, Padre virginal de Jesús y hombre de fe.

\section{Palabras clave:}

José esposo de María, Custodio del redentor, Paternidad de san José, hombre de fe.

\begin{abstract}
The present article aims to reflect on the figure of St. Joseph as the depositary of the mystery of God in the light of Chapter II of the Apostolic Exhortation Redemptoris Custos (Custodian of the Redeemer) in order to re-evaluate the participation of this distinguished Patriarch in the plan of salvation because, as the pope's document itself indicates: "...Joseph of Nazareth participated in this mystery like no other person, except Mary, the Mother of the Incarnate Word. He participated. . . committed to the reality of the same salvific act, being the depository of the same love... (RC 1). Above all, we will know in this article the participation of St. Joseph in the divine mystery as Spouse of Mary, virginal Father of Jesus and man of faith.
\end{abstract}

\section{Keywords:}

Joseph, spouse of Mary, Custodian of the Redeemer, Fatherhood of St. Joseph, man of faith 
1. Redemptoris Custos: una exhortación sobre la doctrina de San José.

La exhortación de Juan Pablo II sobre San José aborda el tema de la vocación y ministerio de san José como "custodio del Redentor" (Redemptoris Custos) desde la perspectiva bíblica para conocer la participación del Esposo de María en el misterio divino, el papel que tiene san José y su lugar en el ámbito del designio redentor como Esposo de María, Padre virginal de Jesús y hombre de fe. Sobre estos títulos reflexionaremos en el presente artículo.

¿Por qué tomar esta exhortación apostólica? Porque la Exhortación Apostólica de Juan Pablo II, en palabras del P. Tarciso Stramare (2004) es considerada la Carta Magna de la doctrina de San José. Su contenido teológico es un punto obligado de referencias y de estudio, si se quiere conocer el rol asignado por Dios a San José en la economía de la salvación y, consecuentemente, honrarlo como conviene".

\section{SAN JOSÉ, ESPOSO DE MARÍA}

Reflexionar acerca de la vocación divina que San José recibió para ser "Esposo virginal de María" no solo es hablar del matrimonio o desposorio de María con José sino también estudiarlo según la línea cristológica de la Redemptoris Custos que dedica una amplia reflexión a la verdad de este matrimonio porque es el fundamento de la paternidad de San José, relación irrenunciable para la concreta actuación de los misterios de la vida escondida de Jesús (Stramare, 2004, p. 47).

Los evangelios, en cuanto son las fuentes bíblicas directas de este matrimonio, nos ayudan a conocer el carácter y alcance teológico del matrimonio de José con María porque por medio de José Dios asegura a su Hijo unigénito una protección paternal. De allí que, aunque la concepción virginal de Jesús queda clara en los evangelios, José es el Padre de Jesús gracias al matrimonio de María (Stramare, 2002, p. 26). El papa Juan Pablo II (1989) nos dice: "El hijo de María es también hijo de José en virtud del vínculo matrimonial que les une: 'A raíz de aquel matrimonio fiel ambos merecieron ser llamados padres de Cristo; no solo aquella madre, sino también aquel padre, del mismo modo que era esposo de su madre, ambos por medio de la mente, no de la carne `" (n. 7).

Conozcamos el testimonio de la Iglesia primitiva sobre el desposorio de José y María en los relatos bíblicos.

José es reconocido en el Evangelio de Mateo con el título singular de "esposo de María", designación que le es oficialmente reconocida en la genealogía de Jesús (Mt $1,16)$ e, inmediatamente después, en el relato de la concepción virginal "...José, su esposo," (v. 19). También, la madre de Jesús, María, es presentada con más frecuencia como desposada con José "...su madre María estaba prometida con José..." (v.18) y en Lucas el ángel se aparece "...a una joven desposada con un hombre llamado José..." (Lc 1,27).

Este desposorio o matrimonio, según "la costumbre del pueblo hebreo, se realizaba en dos etapas: en la primera se celebraba el matrimonio legal (verdadero matrimonio) y, solo después de un cierto periodo, el esposo introducía a la esposa en su casa. Antes de vivir con María, José era su esposo, pero María conservaba en su intimidad el derecho de entregarse a Dios de modo exclusivo" (RC 18).

Para determinar la vocación de San José de ser el padre de Jesús y esposo de 
María tenemos un doble relato que nos explican el designio divino. Para Lucas, la naturaleza de este desposorio encuentra una descripción más amplia y una tradición proveniente del segundo libro de Samuel 7,12 donde se encuentra la profecía más importante del Antiguo Testamento por parte de Natán sobre la estabilidad de la dinastía de David. Se lee en Lucas sobre la anunciación: "Fue enviado por Dios el ángel Gabriel a una ciudad de Galilea, llamada Nazaret a una virgen desposada con un hombre llamado José, de la casa de David, y el nombre de la virgen era María" (Lc 1,26-27). Y a María también el ángel le confirma que a Jesús "el Señor le dará el trono de David, su padre" (Lc 1,32). También el traslado a Belén, donde nacerá Jesús, está motivado por el hecho que José "fue de Judea a la ciudad de David, llamada Belén, para hacerse registrar junto con María su esposa, que estaba encinta, porque José era de la casa y de la familia de David" (Lc 2,2-5).

Si para este evangelista lo importante es poner de manifiesto la concepción virginal y relatar el evento de la anunciación con precisiones históricas, para Mateo su interés es más bien probar su condición mesiánica, como descendiente de David por medio de José. Es por ello que Mateo inicia con la genealogía de Jesús para demostrar que éste si es llamado hijo de David, es gracias a que es hijo de José, pues recibe de él su ascendencia davídica, de allí que se le puede llamar con toda confianza a José el padre de Jesús. Queda claro que "la colocación... de la genealogía y en estrecha dependencia de ella supone, en cambio, otra finalidad, la de justificar la proclamación de una genealogía, en la cual no se afirma, según la legitima espera, que José haya engendrado a Jesús, sino simplemente que José es "el esposo de María, de la que nació Jesús, llamado Cristo" (Mt 1,16). El objeto del relato de
Mateo 1,18-25 no puede ser la revelación de la maternidad virginal de María, que ya está al principio de la anomalía de la genealogía, sino el derecho genealógico de José, seriamente afectado por su exclusión de la concepción, acaecida por obra del Espíritu Santo (v. 18), y sin embargo salvaguardado por su derecho matrimonial: José es padre de Jesús, porque es el esposo de María, su madre. No es posible prescindir de esta lógica, fundamental para la descendencia davídica de Jesús..." (Stramare, 1993, p. 31).

La particularidad de este matrimonio, destinado a acoger al Hijo de Dios, nos introduce directamente al "misterio de

la encarnación" porque ésta se da por acción del Espíritu Santo, artífice de la concepción virginal de Jesús. Las palabras del ángel "Alégrate, llena de gracia, el Señor está contigo" $($ Lc 1,28$)$ provocaron una turbación interior en María y a la vez, le llevaron a la reflexión. Frente a esto, el ángel la tranquiliza y, al mismo tiempo, le revela el designio especial de Dios para ella: "No temas, María, porque has hallado gracia delante de Dios; vas a concebir en el seno y vas a dar a luz un hijo, a quien pondrás por nombre Jesús. Él será grande y será llamado hijo del altísimo, y el Señor Dios le dará el trono de David su padre" (Lc 1,30-32). Estas palabras explican el misterio de la esposa de José: María es virgen en su maternidad.

Por tanto, cuando Dios se dirige a José con las palabras del ángel lo hace como esposo de la Virgen de Nazaret. "El ángel del Señor se le apareció en sueños y le dijo: José, hijo de David, no temas aceptar a María como tu esposa, pues el hijo que espera viene del Espíritu Santo. Dará a luz un hijo, y le pondrás por nombre Jesús, porque él salvará a su pueblo de los pecados" (Mt 1,20-21). 
No cabe duda que lo cumplido en María por obra del Espíritu Santo expresa al mismo tiempo una especial confirmación del vínculo esponsal, existente ya antes entre José y María. Es por ello que María, después de haber escuchado lo que el mensajero había dicho sobre el nacimiento de su hijo, pregunta: "¿cómo sería esto, puesto que no conozco varón?" (Lc 1,34). Enseguida, el ángel le responde: "El Espíritu Santo vendrá sobre ti y el poder del Altísimo te cubrirá con su sombra; por eso el que nacerá será santo y será llamado Hijo de Dios" (Lc 1,35).

Queda claro que la vocación de María no es el camino de una "soltera", sino de una mujer "casada", con todas las implicancias que de ella se derivan. Toda la grandeza de María está en su "Fiat" (hágase) a la voluntad de Dios y en la acción del Espíritu Santo respecto a la concepción virginal del Hijo de Dios hecho carne.

"Por lo que se refiere a la decisión de María en favor de la virginidad nos damos cuenta mejor que se debe a la acción del Espíritu Santo si consideramos la tradición de la Antigua Alianza, en la que Ella vivió y se educó. La aspiración de 'las hijas de Israel', incluso en lo que se refiere al culto y a la ley de Dios, se ponía más bien en el sentido de la maternidad, de forma que la virginidad no era un ideal abrazado e incluso ni siquiera apreciado. Israel estaba totalmente invadido por el sentimiento de espera del Mesías, de forma que la mujer estaba psicológicamente orientada hacia la maternidad. Incluso la función del advenimiento mesiánico, la tendencia personal y étnica subía así el nivel de la profecía que penetraba la historia de Israel, pueblo en el que la espera mesiánica y la función generadora de la mujer estaban estrechamente vinculadas. Así pues, el matrimonio tenía una perspectiva religiosa para las hijas de Israel" (Beteta, 1991, pp. 27-28).

Lo que en la anunciación se ha cumplido en María, ser madre del Verbo encarnado, reafirma al mismo tiempo una especial confirmación del vínculo esponsal existente ya antes entre José y Ella. Este vínculo matrimonial requería también en efecto -supuesta la necesidad del matrimonio para la honrosa inserción del Verbo de Dios en la familia humana y para su reconocimiento como Hijo de David-, que el propósito de conservar la virginidad fuese recíproco, no pudiendo faltar entre los dos cónyuges la más perfecta afinidad, requerida por la perfección de aquel matrimonio. Por tanto, si esta semejanza no fuera perfecta, el amor de amistad se degenera en amor de concupiscencia, que es el amor de lo útil y de lo deleitable. De aquí se infiere que, como María había estado predestinada a la aceptación por la encarnación, así José ha estado también predestinado al matrimonio con María y a todo cuanto le concernía como esposa (Stramare, 2002, p. 76).

¿Cómo entender este doble misterio (maternidad y la virginidad de María) en la persona de San José? La misma Exhortación lo señala diciendo: "Se podría preguntar cómo se concilia este deseo con el Matrimonio. La respuesta viene sólo del desarrollo de los acontecimientos salvíficos, esto es, de la especial intervención de Dios" (RC 18). Acá se encuentra la respuesta para conocer la actuación y participación de José en el Plan divino. Es en el marco de la revelación divina constituido por palabras y hechos en los cuales se ha tenido presente los eventos que han exigido el ejercicio de la paternidad de San José. 
Por ello, el Concilio Vaticano II (1982) nos enseña "... este plan de la revelación se realiza con hechos y palabras intrínsecamente conexos entre sí, de forma que las obras realizadas por Dios en la historia de la salvación manifiestan y confirman la doctrina y los hechos significados por las palabras, y las palabras, por su parte, proclaman las obras y esclarecen el misterio contenido en ellas" (DV 2). Por tanto, José entra a formar parte de una nueva familia que tiene su origen únicamente en Dios. Si José toma consigo a María, no es para iniciar una vida matrimonial en sentido pleno sino para cumplir el mandato de Dios que se indica claramente en Mateo:

"...María, estaba desposada con José y, antes de que conviviesen, se encontró encinta por obra del Espíritu Santo. José, su esposo como era justo y que no quería denunciarla, decidió separarse de ella en secreto. Después de tomar esta decisión, el ángel del Señor se le apareció en sueños y le dijo: José, hijo de David, no temas aceptar a María como tu esposa, pues el hijo que espera viene del Espíritu Santo. Dará a luz un hijo, y le pondrás por nombre Jesús, porque él salvará a su pueblo de los pecados" (Mt 1,18-21).

De todo lo dicho se puede concluir afirmando que la participación de María en el misterio de la encarnación (Lc 1,2639), junto con la de su esposo José (Mt 1,18-25) lleva a no poder separar a ambos ya que, con María, José participa de la fase culminante de la autorrevelación de Dios en Cristo y además es el primero en participar de la fe de la Madre de Dios pues es así como sostiene y acompaña a su esposa en la fe al momento de la divina anunciación (RC 5).
La Redemptoris Cultos, también considera dentro de este matrimonio a José afirmando que este varón justo de Nazaret es sobre todo un "hombre santo". ¿Dónde se sitúa esta santidad de San Josée Esta se sitúa en el texto de Mt 1,19 "José, su esposo, que era justo y no quería denunciarla, decidió separarse de ella en secreto". Para poder comprender la decisión de José es necesario partir de la causa "... María estaba prometida a José y antes de vivir juntos, resultó que esperaba un hijo por la acción del Espíritu Santo" (v. 18)

Es el misterio de la maternidad divina el punto de partida de todo el relato sucesivo: "Después de tomar esta decisión, el ángel del Señor... le dijo: -José hijo de David, no temas aceptar a María como tu esposa, pues el hijo que espera viene del Espíritu Santo. Dará a luz un hijo y le pondrá por nombre Jesús..." (v. 20-21).

La santidad de San José se encuentra en la decisión que va a tomar y en su proceder frente al misterio: ¿Cuál es ésta? El actuar en conformidad al misterio de Dios que el ángel le anunció. Si José, una vez tomado conocimiento del misterio que según los datos bíblicos decide no querer denunciarla sino separarse de ella en secreto es por el temor reverencial. ¿Cómo iba a poder desear a María para sí después de haberla llamado Dios a su propio servicio? La decisión de José de dejar a María es la consecuencia del conocimiento de la maternidad divina. Por ello, José se siente indigno de cohabitar con la madre de Dios y se siente forzado a dejarla. La santidad está en su obrar impulsado por un sentimiento de genuina humildad que le hace aparecer a sus propios ojos como indigno de llamarse padre del niño divino o de tener a aquella mujer, objeto de particular atención 
divina: "José, su esposo, que era justo y no quería denunciarla, decidió separarse de ella en secreto" (Mt 1,19).

Esta explicación es la más aceptada por estar en consonancia con el significado que expresa la Sagrada Escritura cuando nos describe a José como "justo:

\begin{abstract}
"Este término tiene un significado muy rico en la Biblia y por eso es interesante detenernos en él. El justo es el hombre que observa todos los mandamientos divinos, el hombre piadoso, generoso, que no miente, es servicial, cuida al pobre, defiende al oprimido, es fiel a la comunidad, es amigo de Dios. Pero, fundamentalmente, el justo es el hombre que no cumple solamente las normas a un nivel externo, sino ante todo el que se confía en Dios (Dt 8,4; Gn 15,6)" (Collazos, 2004, p. 151-154).
\end{abstract}

José no sólo es el hombre Justo sino también es el "hombre de la acción" pues Dios al escogerlo para tal sublime vocación de ser el padre terreno de su Hijo (Mt 1,20-21) responde con eficacia y generosidad renunciando inmediatamente a cualquier posible expectativa personal que tuviera entonces para adherirse al plan de Dios. No se consigna ninguna palabra en los evangelios respecto a José pues inmerso en la contemplación de lo divino no titubeo sino solo actuó para participar de la vocación paterna que se le había concedido al momento de poner el nombre de Jesús al niño que nacerá (Mt 1,25), frente al edicto de empadronamiento cumpliendo con la tarea de inscribir oficialmente el nombre "Jesús hijo de José de Nazaret" (Jn 1,45) en el registro del imperio" (RC 9); frente al nacimiento de su hijo tuvo que encaminarse a Belén con su esposa a punto de dar a luz (Lc 2,6-7) siendo testigo ocular del mismo (RC 10) y en los demás acontecimientos será confiado a José la tarea de ser el depositario y cooperador del misterio providencial de Dios: la visita de los pastores (Lc 2,20), la adoración de los reyes magos (Mt 2,11-12), la huida a Egipto haciendo imposible el retorno a su patria, Nazaret por las amenazas de muerte (Mt 2,13-15), el regreso a Nazaret años después (Mt 2,22-23), el ocultamiento de Jesús hasta el momento de su manifestación pública (Lc 2,52) como la pérdida y el encuentro de Jesús en el templo se desarrolla en el ámbito de la sagrada familia a la vista de San José que tenía la alta misión de criarle, alimentarle, vestir e instruir que era lo que corresponde a los deberes propios de todo padre (LC 2,51). La muerte de José o su tránsito no está mencionada en los evangelios pues la Redemptoris Cultos considera aquellos misterios de la vida escondida de Jesús.

\section{PATERNIDAD DE SAN JOSÉ}

La Exhortación Apostólica Redemptoris Custos en los números 7 y 8 nos presentan la figura de San José en función de la encarnación y guardando una estrecha relación a su función paterna. Esta paternidad también está vinculada con su vocación esponsal y con la paternidad misma de Dios.

\section{José: esposo-padre}

En el número 7, la exhortación nos presenta la preocupación de Dios Padre para que su Hijo divino, al venir al mundo, tenga un hogar que le reciba y donde pueda vivir. Por ello, este número es sumamente importante para comprender la grandeza de la "misión de San José" como padre de Jesús que tiene su fundamento en el verdadero matrimonio con María, Madre del verbo: "...el matrimonio con María es 
el fundamento jurídico de la paternidad de José. Es este número donde Juan Pablo II comenta:

"En esta familia José es el padre: no es la suya una paternidad derivada de la generación; y, sin embargo, no es «aparente» o solamente «sustitutiva», sino que posee plenamente la autenticidad de la paternidad humana y de la misión paterna en la familia. En ello está contenida una consecuencia de la unión hipostática: la humanidad asumida en la unidad de la Persona divina del Verbo-Hijo, Jesucristo. Junto con la asunción de la humanidad, en Cristo está también «asumido» todo lo que es humano, en particular, la familia, como primera dimensión de su existencia en la tierra. En este contexto está también «asumida» la paternidad humana de José" (RC 21).

Este derecho de paternidad es jurídicamente dependiente de la verdad del matrimonio contraído con María. Por ello, desde el momento que el ángel le revela a José su ministerio, ordenándole recibir en su casa a María e imponer el nombre al niño (Mt 1,20-25), su vida no tiene otro sentido y razón que la del servicio del Niño y de la Madre. De allí que en el paralelismo entre el anuncio "...y le pondrás por nombre Jesús" (Mt 1,21 ) y ejecución "...hizo lo que el ángel del Señor le había mandado...y sin tener relaciones conyugales ella dio a luz, un hijo, al que José puso por nombre Jesús" (Mt 1,24-25) requiere que la primera enunciación "recibió en su casa" no se separe de las otras porque si la profecía de Isaías había surgido fue para confirmar la fe de Israel en el Señor.
"Todo esto ocurrió para que se cumpliera lo que había anunciado el Señor por el profeta: ‘la virgen concebirá y dará a luz un hijo la que pondrán por nombre Emmanuel (que significa Dios con nosotros), el anuncio del ángel que le manda ante todo a José imponer el nombre al niño, será para probar la condición mesiánica del niño y poner el acento en el nombre del redentor presente en Jesús (Stramare, 2001, p. 11).

Por tanto, si el mensajero divino se dirige a José como esposo de María lo hace, a su vez, para confiarle la tarea de desempeñar la función de un padre terreno respecto al de Jesús, el Hijo de María (RC 3). Toda la paternidad y presencia de José en la sagrada familia está requerida y justificada por su relación con Jesús. De allí que la Exhortación sobre San José señala los momentos más relevantes de la vida de Jesús, en los cuales José va a servir directamente a la persona y misión de Jesús (RC 8-16).

"La RC se presenta de hecho como un pequeño tratado sobre los misterios de la vida escondida de Jesús, pues si no los considera por sí mismos, lo hace, en función del tema de la exhortación apostólica, que está en relación al misterio de San José. Lo encontramos evidencias en el censo (n.9), el nacimiento en Belén (n. 10), la circuncisión (n. 11), la imposición del nombre (n. 12), la presentación de Jesús al templo (n. 13), la huida a Egipto (n. 14), la permanencia de Jesús en el templo (n. 15), el sustento y educación de Jesús en Nazaret (n. 16). Están presentes también el matrimonio de María y José (n. 
7), la Santa familia (n. 7-21), el trabajo (n. 22)" (Stramare, 2002, p.21).

\section{José: custodio del redentor.}

El ministerio que realiza San José es de ser el custodio del redentor. El calificativo "custodio" para San José se debe reflexionar y desarrollar seguido de otro calificativo "minister salutis" (ministro de salvación).

"El título `padre` reconocido por el Espíritu Santo a José mediante la autoridad de las Escrituras, ha sido ciertamente enaltecido por Jesús durante su vida terrestre a través de la obediencia a su padre (cf. Lc 2,51), pero ha sido enaltecido también de manera ejemplar por José, que ha hecho de su vida un servicio a su hijo: "servir a Cristo fue su vida, servirlo en la dedicación más completa, servirlo con amor y por amor" (Pablo VI, 1966, p. 2).

Este título que se le da a San José, custodio del Redentor, es también el título de la exhortación que busca situar en el misterio de la redención para afirmar que José es el depositario y cooperador del misterio providencial de Dios (RC 14). Este título describe la paternidad de San José quien ha satisfecho la alta misión de criarle, esto es alimentar, vestir e instruir a Jesús en la Ley y en un oficio, como corresponde a los deberes propios del padre (RC16) pero no ha contribuido simplemente a criar un niño, con una colaboración que permanecería puramente extrínseca a la redención, sino también ha cooperado al gran misterio de la redención mediante el ejercicio de su paternidad a la misma del Redentor actuando "ex officio" como ministro de los misterios mismos. Por tanto, José es considerado ministro de la salvación (Stramare, 2002, p. 90-92).

En cuanto a las tareas que ejerció San José como padre respecto a Jesús como ministro de la salvación podemos citar algunas que en palabras del P. Tarciso Stramare, OSJ, ex director del Movimiento Josefino Internacional:

- "Es José quien ha honrado con el título de esposo de maría su divina maternidad,

- Es José quien ha transmitido a Jesús la descendencia davídica, indispensable para ser reconocido como "el Cristo",

- Es él quien ha insertado a Jesús entre los ciudadanos del mundo, inscribiéndolo en el registro de la población de Belén con ocasión del censo Augusto,

- Es José quien ha introducido a Jesús en el pueblo de la Alianza, proveyendo al rito de la circuncisión,

- Es él quien ha impuesto al Verbo de Dios encarnado, por el mandato del Padre y con pleno derecho legal, el nombre de Jesús, que lo designa como Emanuel,

- Es él quien lo ha presentado al Padre cumpliendo el ofrecimiento ritual del Primogénito y participando en la ratificación de tal ofrecimiento hechas a los doce años con ocasión de su permanencia en el templo,

- Él es quien ha protegido al Niño y a su madre durante el viaje al 
exilio y durante su ida de prófugos en Egipto,

- Él es quien como padre nutricio ha cuidado de su mantenimiento, procurándole alimento y vestido, y ayudándole a crecer,

- Es él quien puso le ha enseñado un oficio y le ha dado la condición de hijo del carpintero,

- Es él quien lo ha educado a la oración y al conocimiento de la vida y del mundo" (Stramare, 2002, pp. 93-94).

Es el servicio al Redentor, la verdadera misión de José porque desde el momento en que el ángel le revela su ministerio, ordenándole recibir en su casa a María e imponer el nombre al Niño (Mt 1,20-25), su vida no tiene otro sentido y razón que la del servicio del Niño y de la Madre. Pablo VI es muy expresivo al respecto:

"San José puso de inmediato a disposición de los designios divinos su libertad, su legítima vocación humana, su felicidad conyugal, aceptando de la familia la condición, la responsabilidad y el peso, y renunciando por un incomparable amor virginal, al amor natural conyugal que la constituye y alimenta, para ofrecer así con sacrificio total toda su existencia a las imponderables exigencias de la sorprendente venida del Mesías" (Pablo VI, 1969, p. 1)

Por tanto, el "ministerio de san José" fue un ministerio verdaderamente sublime, que el hijo de Dios ha sido humildemente aceptado y honrado con su obediencia. Esto es lo que nos dice el Papa León XIII en la carta encíclica Quamquam pluries:

"Él se impone entre todos por su augusta dignidad, dado que por disposición divina fue custodio $\mathrm{y}$, en la creencia de los hombres, padre del Hijo de Dios. De donde se seguía que el Verbo de Dios se sometiera a José, le obedeciera y le diera aquel honor y aquella reverencia que los hijos deben a su propio padre" $\left(\mathrm{N}^{\circ} 3\right)$.

\section{JOSÉ HOMBRE DE FE}

Todo el camino de San José nos dice la Redemptoris Custos:

"... fue una peregrinación en la fe, José al igual que María, permaneció fiel a la llamada de Dios hasta el final. La vida de ella fue el cumplimiento hasta sus últimas consecuencias de aquel primer "fiat" pronunciado en el momento de la anunciación, mientras que José... en el momento de su anunciación no pronunció palabra alguna. Simplemente él hizo como el ángel le había mandado (Mt 1,24). Y ese primer "hizo" es el comienzo del camino de fe de José" (RC 17).

Precisa la Redemptor Custos que "en honor a la verdad José no respondió al anuncio del ángel como María; pero hizo como le había ordenado el ángel del Señor y tomó consigo a su esposa. Lo que él hizo es genuina obediencia de la fe" (RC 4). Por tanto, lo que hizo es auténtica obediencia de la fe lo cual le unió de forma especial a la fe de María.

La prueba de fe de María está en la anunciación porque allí se dice que la 
virgen María se turbó ante las palabras del ángel "(Lc 1,38), mientras que José hizo lo que le había mandado el ángel del Señor: "... hijo de David, no temas aceptar a María como tu esposa pues el Hijo que espera viene del Espíritu Santo... Cuando José se despertó del sueño, hizo lo que el ángel del Señor le había mandado: tomó consigo a su esposa (Mt 1,20.24).

Por tanto, lo que José hizo es probada obediencia de la fe que se unió en modo particular a la fe de María pero el Papa indica citando la constitución dogmática Dei Verbum lo que el concilio dice al respecto: "Cuando Dios se revela hay que prestarle la obediencia de la fe, por la que el hombre se confía libre y totalmente a Dios, prestando a Dios revelador el homenaje del entendimiento y de la voluntad y asintiendo voluntariamente a la revelación hecho por él" (DV 5).

Desde el comienzo de su misión, José entró junto a María en el "camino de fe" logrando actuar en plena sintonía con su esposa unidos por el mismo acto de obediencia: como esposo se encontró junto a ella desde el primer momento de la anunciación, fue guardián fiel de la Madre y del Niño durante la fuga a Egipto, cuando se hizo necesario escapar de la crueldad de Herodes, luego fue jefe de familia en la casa de Nazaret, donde el hijo de Dios progresaba en sabiduría, estatura y gracia ante Dios y los hombres (Lc 1,52$)$ hasta sus 30 años de edad.

En cuanto a este camino de fe que San José participa nos dice la encíclica: "que lo que hizo José lo unió en modo particularísimo a la fe de María. Aceptó como proveniente de Dios lo que ella ya había aceptado en la anunciación" (RC 4) y además de este modo "sostiene a su esposa en la fe de la divina anunciación"
(RC 5). Por tanto, José fue el primero en participar de la fe de la Madre de Dios convirtiéndose en el primer depositorio singular del misterio escondido desde siglos en Dios.

El camino de fe de José llegará a su término cuando Dios disponga que se retire, sencilla y silenciosamente como había vivido. Ya habiéndose entregado al misterio de la encarnación preparó lo mejor para el Hijo de Dios que nacería en su hogar. La peregrinación en la fe de San José concluirá "antes de que María se detenga ante la cruz en el Gólgota y antes de que Ella, una vez vuelto Cristo al Padre, se encuentre en el cenáculo de Pentecostés el día de la manifestación de la Iglesia en el mundo" (RC 6).

\section{CONCLUSIONES}

A modo de conclusión se puede señalar que el primer aspecto de la vocación de San José como esposo de María está en el momento del anuncio a María y su consentimiento (cf. Lc 1,28-38) el cual encuentra un adecuado paralelo y oportuna correspondencia en el anuncio a José y en su consentimiento (cf. Mt 1,18-25) al aceptar a Jesús como su Hijo: "Dará a luz un hijo y tú le pondrás el nombre de Jesús, porque él salvará a su pueblo de sus pecados" (Mt 1,25), estableciendo una comunión de vida con María que el evangelio de Lucas deja traslucir al presentar a los padres de Jesús estrechamente unidos en los episodios del nacimiento (Lc 2,6-20), la circuncisión $(2,21)$, la presentación de Jesús en el templo $(2,22-38)$, en el encuentro entre los doctores $(2,41-50) \mathrm{y}$ la vuelta a Nazaret (2,39-40.51-52).

La presentación de los misterios revela el significado y la importancia que tienen para evidenciar la tarea que San 
José ha realizado al servicio del verbo encarnado quien ha sido llamado por Dios para servir directamente la persona y misión de Jesús mediante el ejercicio de su paternidad. José fue un hombre de vida oculta y vocación silenciosa, pero tras el anuncio del ángel resultó que esperaba un hijo, por obra del Espíritu Santo a lo cual se dedicó hasta el final de su vida.

El amor paterno de José hacia su hijo es expresado concretamente al haber hecho de su vida un ministerio (servicio), al constituirse en el custodio del redentor, en favor del misterio de la redención. Por ello, la misión redentora de Jesús está unida a José al haber hecho uso de la autoridad legal, que le correspondía sobre la Sagrada Familia, para hacerle don total de si, de su vida y de su amor. José está unido a la maternidad de María, puesto que participa desde el primer instante de la fe de la Madre de Dios y haciéndolo así, la sostiene en la fe de la divina anunciación.

Y, por último, el camino de fe de San José está unido directamente a la persona y misión de Jesús mediante el ejercicio de su paternidad.

\section{REFERENCIAS}

Beteta, P (1991) La vocación de San José y la nuestra, explicadas por Juan Pablo II. Palabra.

Biblia de América (2004). Manual para educadores y agentes de pastoral. PPC.
Collazos, C. (2004). "San José modelo de vida interior". En Congreso: San José ante los desafíos del Tercer Milenio. GRAMBS.

Juan Pablo II (1989). San José (Redemptoris Cultos), salesiana.

León XIII (1989). Quamquam pluries. Sobre la devoción a San José. Libreria Editrice Vaticana.

Pablo VI (1965). "Constitución Dogmática Dei Verbum". En Vaticano II. Documentos. BAC.

Pablo VI (1966). Fiesta de San José, Patrono de la Iglesia Universal.

Stramare, T. (1993). San José en la historia de la salvación. Delegación Nacional del Óvolo de san Pedro.

Stramare, T (2002). La vía de San José. Espiritualidad Josefina. Delegación Nacional del Óvolo de San Pedro.

Stramare, T. (2004). "San José ministro de la salvación a la luz de la exhortación Apostólica Redemptoris Custos". En Congreso: San José ante los desafíos del Tercer Milenio (5, 6 y 7 de marzo). GRAMBS.

Fecha de recepción: 11-11-2020 Fecha de aceptación: 15-11-2020 